\title{
Mosaic Trisomy 16 Confined to Placenta: Pregnancy Outcome and Postnatal Follow up
}

\author{
Rosita Verteramo ${ }^{1 *}$, Stefania Bigoni ${ }^{2}$, Maria Paola Gentile ${ }^{3}$ and Pantaleo Greco ${ }^{1}$ \\ ${ }^{1}$ Department of Morphology, Surgery and Experimental Medicine, Section of Obstetrics and Gynecology, University of Ferrara, \\ Italy
}

${ }^{2}$ Medical Genetic UOL, University of Ferrara, Italy

${ }^{3}$ Department Reproduction and Growth, Neonatal Intensive Care Unit and Neonatology, University of Ferrara, Italy.

*Corresponding author: Rosita Verteramo, Department of Morphology, Surgery and experimental Medicine, Section of Obstetrics and Gynecology, University of Ferrara, Via Aldo Moro 8, Cona, 44124 Ferrara, Italy

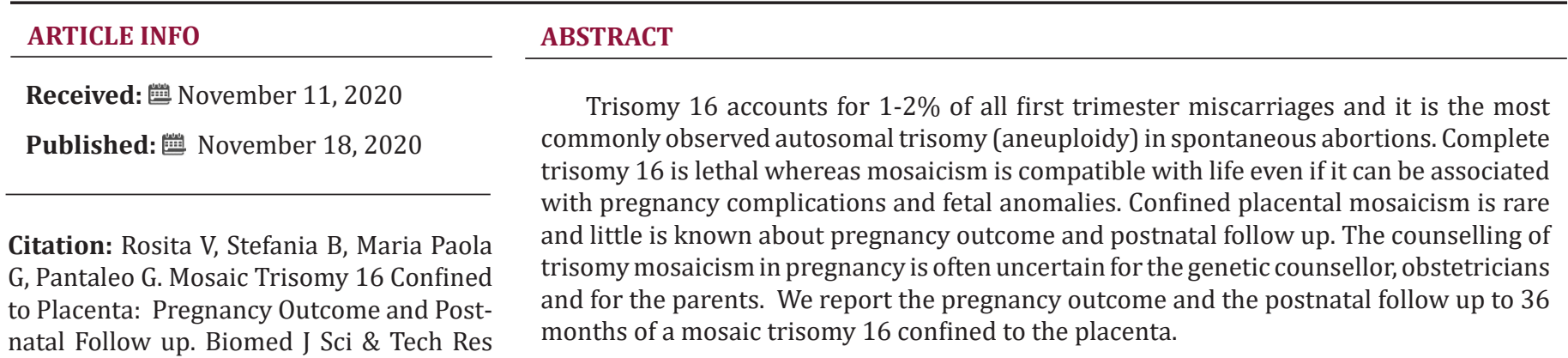

32(1)-2020. BJSTR. MS.ID.005180.

Keywords: Mosaic trisomy 16; Prenatal diagnosis; IUGR

\section{Case report}

The mother was a 29-year-old Caucasian healthy woman gravida 1, para 0 and she was referred to prenatal diagnosis to $\mathrm{S}$. Anna University Hospital, Ferrara at 20 weeks of gestation for a intrauterine growth restriction and suspected skeletal dysplasia. A detailed ultrasound examination of fetus was performed according to current Guidelines (International Society of Ultrasound in Obstetrics and Gynecology Guidelines 2011; Italian Society of Ultrasound in Obstetrics and Gynecology Guidelines 2015) and the presence of a severe intrauterine growth restriction in absence of other significant congenital abnormalities was confirmed. A single umbilical artery was diagnosed. Cytogenetic analysis was performed at 20 weeks, both on fetal blood and amniotic fluid, and revealed a normal female karyotype (46 XX). A fetal ultrasound scan at $25+5$ weeks revealed a severe IUGR (fetal biometry $<3$ rd percentile); femur/foot length ratio was 0.73 . End diastolic flow was absent. Sonographic scan of the placenta showed cystic areas. A scan at 27+1 weeks proved BPD $58 \mathrm{~mm}$ (<3rd centile), HC 213 $\mathrm{mm}$ ( $<3 \mathrm{rd}$ centile), AC $178 \mathrm{~mm}$ ( $<3 \mathrm{rd}$ percentile), femur length $32 \mathrm{~mm}$ ( $<3$ rd centile), IPAO 2.03 ( $>2$ DS above the mean), IPACM
1.45 ( $<-3$ SD). Ultrasound examinations were then performed twice a week. Caesarean delivery was performed at $32^{\wedge}+1$ weeks of gestation because of increasingly abnormal Doppler flow in the umbilical artery (end diastolic flow was absent, sometimes reversed) and severe intrauterine growth restriction. Birth weight of the female baby was $804 \mathrm{~g}$ (<3rd centile), Apgar scores were 7-9. The placenta weight was $115 \mathrm{~g}$. Placental examination confirmed the single umbilical artery; placental histology demonstrated infarction, vascular thrombosis, fibrin deposition and cystic areas. Cytogenetic analysis of the placenta showed a female karyotype with complete and homogeneous trisomy of the chromosome 16. The baby was hospitalized for 2 months after birth.

During this first period of life, several investigations (audiological and ophthalmological evaluations, cerebral and renal ultrasound scans) gave normal results. At the dysmorphological evaluation, performed soon after birth, a proportioned short stature was observed in absence of any significant dysmorphisms. At the neurological evaluation before discharging it was observed mild neurovegetative instability and a poor general movements 
(GMs) pattern with poor behavioral modulation. All the genetic investigations (blood and skin fibroblasts karyotype, with extensive work up), segregation analysis of the chromosome 16 (on DNA extracted from lymphocytes and fibroblasts) were normal. At 2 months after birth, the baby weight was $2240 \mathrm{~g}\left(<3^{\circ}\right.$ centile), length was $42.5 \mathrm{~cm}\left(<3^{\circ}\right.$ centile $)$ and CC was $33 \mathrm{~cm}\left(10-25^{\circ}\right.$ centile). The child was referred to the local neonatal neurodevelopment follow-up outpatient-room. Bilateral congenital coxa vara was diagnosed and physical therapy was performed twice a week. At 12 months she could sit unsupported and her weight was $7000 \mathrm{~g}$. At 26 months the baby walked unsupported only for short distances; her behavioral development was normal, her weight was 9,350 kg ( $5^{\wedge}$ th centile), length was $79 \mathrm{~cm}$ ( $5^{\wedge}$ th centile) and CC was $45.5 \mathrm{~cm}$ (5-25^th centile). At 36 months the child can independently walk, run and climb stairs, she is bilingual and regularly go to the nurse.

\section{Discussion}

In literature several cases of mosaic trisomy 16 are reported. Only some studies report a complete postnatal follow-up. Trisomy 16 accounts for $1-2 \%$ of all first trimester miscarriages and it is the most commonly observed autosomal trisomy (aneuploidy) in spontaneous abortions [1]. Trisomy 16 is determined by the presence of an extra chromosome 16 of maternal origin, the most frequent cause is an error during maternal meiosis I [2]. Complete trisomy 16 is lethal whereas mosaicism is compatible with life even if it can be associated with pregnancy complications and fetal anomalies [3]. Chromosomal mosaicism is the presence of two or more cell lines in an individual; a confined placental mosaicism (CPM) for trisomy 16 can be diagnosed through chorionic villus sampling (CVS). In the majority of cases of CPM the fetus is structurally normal $[4,5]$. CPM can be associated with placental insufficiency, oligohydramnios, intrauterine growth restriction and it has been described in association with a variable spectrum of Multiple Congenital Anomalies (single umbilical artery, hydrocephalus) and dysmorphisms [6-8]. CPM is also associated with elevated maternal serum HCG [5]. Data concerning long term outcome of the babies are lacking [2].

Johnson et al. [5] report a case of trisomy 16 diagnosed at CVS; the pregnancy was voluntary terminated at 21 weeks of gestation because of structural fetal anomalies (large left-sided diaphragmatic hernia containing liver and bowel and bilateral sandal gap deformity); sonographic scan revealed single umbilical artery and post mortem examination showed VATER structural anomalies. FISH demonstrated very low-level mosaicism in fetal tissue. Sanchez et al. report one case of trisomy 16 apparently confined to placenta associated to intrauterine growth restriction and fetal anomalies (hypokinesia, enlarged cisterna magna, dilatation of cerebral lateral ventricle, and hypoplasia of the corpus callosum). A single umbilical artery was present. Preterm birth occurred and the fetus died. Samples of fetal tissues were taken for cytogenetic and molecular genetic analysis, but no trisomy cells were found. Uniparental disomy (UPD) was also excluded. Mosaicism confined to placenta associated to IUGR, single umbilical artery and congenital heart defect is also reported by Astner et al. [3]. The authors described a thick placenta and multiple round placental cysts at the second trimester sonographic scan that disappeared in the third trimester.

A caesarean section was performed at $36+5$ weeks, postnatal follow up to two years showed normal neurological development and growth. A review of the literature is presented by Langlois et al. [9]. They reported 19 cases of trisomy 16 detected on CVS and 17 cases of trisomy 16 detected on amniocentesis. In the cases detected on CVS (trisomy 16 confined to placenta) they found 1 pregnancy complicated by IUGR, 3 cases of abnormal maternal HCG levels, 2 fetuses with hypospadia, 1 case of left renal agenesia, 1 case of congenital heart defect (ASD and VSD) and 1 case of thyroid agenesia. Postnatal follow up showed normal development for all the babies; in one case it is reported delayed speech development. In the 17 cases of trisomy 16 detected on amniocentesis they reported 7 cases of multiple congenital anomalies (including congenital heart defect) and postnatal follow up showed global development delay in 4 cases (23.5\%). In our case placenta karyotype was $47 \mathrm{XX}+16$, whereas the baby karyotype was normal, with no evidence of UPD16. Intrauterine growth restriction was present from the 20th week of gestation as a sign of premature placental insufficiency. Cystic areas were found at the sonographic and histological examination of the placenta. As reported in literature the sonographic detection of hyperplastic placenta with multiple cysts and IUGR is relating to chromosomal aneuploidies in placental tissue [3]. So, it is necessary to underline the importance of the genetic study of the placenta. The majority of prenatally diagnosed trisomy 16 mosaic confined to placenta cases have a good postnatal outcome [9].

In this report, CPM is associated to severe IUGR and extremely neonatal low birthweight; patient's hospitalization period was complicated only by early feeding intolerance. At 36 months follow up, motor, cognitive and behavioral development of the baby are apparently normal after a transient motor delay. We can hypothesize that, based on the results of genetic investigations, this clinical pattern could be explained, as first hypothesis, with a prenatal suffering due to the presence of complete and homogeneous trisomy 16 at the placental level that can have compromised fetal growth. Unlikely, the hypothesis of a low-level mosaicism has been largely excluded by the performed genetic investigations (blood and skin fibroblasts karyotype extensive workup). A longer follow-up will be needed to rule-out "minimal brain damage" and metabolic complications.

Some studies and case reports [10-12] have been published about pregnancies outcome and postnatal follow up and others will have to be published to optimize antenatal care and to better direct the clinician at the time of counselling. 


\section{References}

1. Hsu WT, Shchepin DA, Mao R, Berry-Kravis E, Garber AP, et al. (1998) Mosaic trisomy 16 ascertained through amniocentesis: evaluation of 11 new cases. Am J Med Genet 80(5): 473-480.

2. Sánchez JM, López De Díaz S, Panal MJ, Moya G (1997) Severe fetal malformations associated with trisomy 16 confined to the placenta. Prenat Diagn 17(8):777-779.

3. Astner A, Schwinger E, Caliebe A, Jonat W, Gembruch U (1998) Sonographically detected fetal and placental abnormalities associated with trisomy 16 confined to the placenta. A case report and review of the literature. Prenat Diagn 18(12): 1308-1315.

4. Coman D, Gardner RJ, Pertile MD, Kannu P (2010) Trisomy 16 mosaicism at chorionic villus sampling and amniocentesis with a normal physica and intellectual outcome. Fetal Diagn Ther 28(2): 117-118.

5. Johnson P, Duncan K, Blunt S, Bell G, Ali Z, et al. (2000) Apparent confined placental mosaicism of trisomy 16 and multiple fetal anomalies: case report. Prenat Diagn 20(5): 417-421.

6. Chareonsirisuthigul T, Worawichawong S, Parinayok R, Promsonthi $\mathrm{P}$ Rerkamnuaychoke B (2014) Intrauterine growth retardation fetus with trisomy 16 mosaicism. Case Rep Genet: 739513.

\section{ISSN: 2574-1241}

DOI: 10.26717/BJSTR.2020.32.005180

Rosita Verteramo. Biomed J Sci \& Tech Res

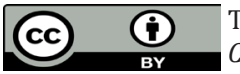

This work is licensed under Creative Commons Attribution 4.0 License

Submission Link: https://biomedres.us/submit-manuscript.php
7. Rieubland C, Francis D, Houben L, Corrie S, Bankier A, et al. (2009) Two cases of trisomy 16 mosaicism ascertained postnatally. Am J Med Genet 149A(7): 1523-1528.

8. Petracchi F, Igarzabal L, Crespo ML, Gadow E (2009) Trisomy 16 detected by first trimester screening. Prenat Diagn 29(12): 1175-1176.

9. Langlois S, Yong PJ, Yong SL, Barrett I, Kalousek DK, et al. (2006) Postnatal follow-up of prenatally diagnosed trisomy 16 mosaicism. Prenat Diagn 26(6): 548-558.

10. Wan JH, Han J, Yang YD, Li DZ (2019) Detection of confined placental trisomy 16 using non-invasive prenatal testing in a pregnancy associated with intrauterine growth restriction and normal karyotype. Eur J Obstet Gynecol Reprod Biol 233: 81-83.

11. Grau Madsen S, Uldbjerg N, Sunde L, Becher N (2018) Danish Fetal Medicine Study Group; Danish Clinical Genetics Study Group. Prognosis for pregnancies with trisomy 16 confined to the placenta: A Danish cohort study. Prenat Diagn 38(13): 1103-1110.

12. Donato XC, Brechard MP, Francois Renard P, Hairion D, Quarello E, et al. (2018) Pregnancy course and outcomes in mosaic trisomy 16 confined to the placenta: A case series. Prenat Diagn 38(12): 924-927.

$\begin{array}{ll}\text { BIOMEDICAL } & \text { Assets of Publishing with us } \\ \text { RESEARCHES } & \text { - Global archiving of articles } \\ \text { - Immediate, unrestricted online access } \\ \text { - Rigorous Peer Review Process }\end{array}$

